\title{
O impacto na qualidade de vida nos indivíduos pós Covid-19: O que mudou?
}

\author{
The impact on quality of life on individuals after Covid-19: What has changed? \\ El impacto em la calidad de vida de las personas después del Covid-19: ¿Que cambió?
}

Recebido: 14/10/2021 | Revisado: 22/10/2021 | Aceito: 28/10/2021 | Publicado: 01/11/2021

\author{
Mylla Crislley Trindade Carvalho \\ ORCID: https://orcid.org/0000-0002-6147-7836 \\ Universidade Tiradentes, Brasil \\ E-mail: myllatcarvalho21@gmail.com \\ Bruna Maria Barros de Jesus \\ ORCID: https://orcid.org/0000-0003-1911-7674 \\ Universidade Tiradentes, Brasil \\ E-mail: brubarross31@gmail.com \\ Vinicius Leite de Castro \\ ORCID: https://orcid.org/0000-0003-3001-8554 \\ Universidade Tiradentes, Brasil \\ E-mail: viniciuslcastro@yahoo.com.br \\ Leda Maria Delmondes Trindade \\ ORCID: https://orcid.org/0000-0003-4300-4274 \\ Universidade Tiradentes, Brasil \\ E-mail: leda.maria@souunit.com.br
}

\begin{abstract}
Resumo
Objetivos: Avaliar a qualidade de vida relacionada à saúde dos pacientes acometidos pelo Covid -19 , através do instrumento SF-36. Métodos: Estudo transversal e observacional realizado entre os meses de janeiro e agosto de 2021. A amostra foi constituída por 221 participantes, com base na aplicação do questionário SF-36, avaliando-se a qualidade de vida em oito domínios naqueles pacientes atendidos pelo Instituto de Promoção e de Assistência à Saúde de Servidores do Estado de Sergipe - IPESAÚDE, diagnosticados com o Covid-19 mediante teste RT-PCR positivo e que tenham sido cadastrados e acompanhados pelo projeto "Monitora Corona". O nível de significância estatística adotado foi de 0,05 e o software utilizado o R Core Team 2021. Resultados: Um total de 221 pacientes foram incluídos no estudo. Destes, 63,8\% eram do sexo feminino, com idade média de 43,6 anos. Os domínios apontaram os determinados valores: Capacidade Funcional - 68,5 DP (desvio-padrão); Limitação por Aspectos Físicos - 48,9 DP; Dor - 55,5 DP; Estado Geral de Saúde - 54,9 DP; Vitalidade - 50,5 DP; Aspectos Sociais - 53,5 DP; Limitação por Aspectos Emocionais - 43,4 DP; Saúde Mental - 54,3 DP. Considerações finais: Na amostra avaliada, a maioria dos pacientes foram constituidos por mulheres adultas jovens com a qualidade de vida e saúde mental significativamente alteradas pela infecção pelo SARS-CoV-2 e seu tratamento. Diante o exposto, sugere-se necessidade de enfrentamento das repercussões negativas da saúde mental com propostas de organização e implementação de serviços de atenção à saúde da população.
\end{abstract}

Palavras-chave: Qualidade de vida; Saúde Mental; Covid-19.

\begin{abstract}
Objectives: To evaluate the quality of life of patients affected by Covid -19, using the SF-36 instrument. Methods: Cross-sectional and observational study carried out between January and August 2021. The sample consisted of 221 participants, based on the application of the SF-36 questionnaire, evaluating the quality of life in eight domains in those patients seen by the Institute for Promotion and Health Care Assistance to Servants of the State of Sergipe IPESAÚDE, diagnosed with Covid-19 by positive RT-PCR test and who were enrolled and followed-up by the "Monitora Corona" project. The level of statistical significance adopted was 0,05 and the software used R Core Team 2021. Results: A total of 221 patients were included in the study. Of these, $63.8 \%$ were female, with a mean age of 43.6 years. The domains showed the following values: Functional Capacity - 68.5 SD (standard deviation); Limitation by Physical Aspects - 48.9 SD; Pain - 55.5 SD; General State of Health - 54.9 SD; Vitality - 50.5 SD; Social Aspects 53.5 SD; Limitation by Emotional Aspects - 43.4 SD; Mental Health - 54.3 SD. Final considerations: In the sample evaluated, most patients were young adult women with quality of life and mental health significantly altered by SARS-CoV-2 infection and its treatment. In view of the above, we suggest the need to face the negative repercussions of mental health with proposals for organization and implementation of health care services for the population.
\end{abstract}

Keywords: Quality of Life; Mental Health; Covid-19. 
Research, Society and Development, v. 10, n. 14, e219101421769, 2021

(CC BY 4.0) | ISSN 2525-3409 | DOI: http://dx.doi.org/10.33448/rsd-v10i14.21769

\begin{abstract}
Resumen
Objetivos: Evaluar la calidad de vida relacionada con la salud de los pacientes afectados por Covid -19, utilizando el instrumento SF-36. Métodos: Estudio transversal y observacional realizado entre enero y agosto de 2021. La muestra estuvo conformada por 221 participantes, a partir de la aplicación del cuestionario SF-36, evaluando la calidad de vida en cada dominio de los pacientes atendidos por el Instituto de Promoción y Asistencia a la Salud de los Servidores del Estado de Sergipe - IPESAÚDE, diagnosticados con Covid-19 por prueba RT-PCR positiva y que fueron registrados y monitoreados por el proyecto "Monitora Corona". El nivel de significación estadística adoptado fue del 0,05 y el software utilizado R Core Team 2021. Resultados: Se incluyeron en el estudio un total de 221 pacientes. De ellos, el $63,8 \%$ eran mujeres, con una edad media de 43,6 años. Los dominios mostraron los siguientes valores: Capacidad Funcional - 68,5 DE (desviación estándar); Limitación por Aspectos Físicos - 48,9 DE; Dolor - 55,5 DE; Estado de Salud General - 54,9 DE; Vitalidad - 50,5 DE; Aspectos Sociales - 53,5 DE; Limitación por Aspectos Emocionales 43,4 DE; Salud Mental - 54,3 DE. Consideraciones finales: En la muestra evaluada, la mayoría de los pacientes eran mujeres adultas jóvenes con una calidad de vida y una salud mental significativamente alteradas por la infección por SARS-CoV-2 y su tratamiento. Esto sugiere la necesidad de abordar las repercusiones negativas de la salud mental con propuestas de organización e implementación de servicios de atención sanitaria para la población.
\end{abstract}

Palabras clave: Calidad de Vida; Salud Mental; Covid-19.

\title{
1. Introdução
}

Em dezembro de 2019, surge em Wuhan, na China, uma nova apresentação de pneumonia com alta taxa de morbidade e letalidade ocasionada pelo Coronavírus da Síndrome Respiratória Aguda Grave 2 (SARS-CoV-2), que rapidamente atraiu atenção mundial pelo alto poder de transmissão e infectividade (Dias et al., 2021). Em 30 de janeiro de 2020, a Organização Mundial da Saúde (OMS) declarou essa doença como uma 'emergência de saúde pública de interesse internacional' (Lima et al., 2020). Segundo a OMS, o Covid-19 gerou uma das maiores pandemias do mundo moderno, atingindo quase duzentos milhões de pessoas e provocando quase quatro milhões de mortes (Brasil - OPAS/OMS | Organização Pan-Americana da Saúde, n.d.).

Assim, com o intuito de evitar a disseminação descontrolada da doença, foram adotadas medidas que se mostraram eficazes em sua contenção. Nessa direção, foram sancionadas ações como o isolamento dos casos suspeitos e distanciamento social, dando início a quarentena com objetivo de conter a mobilidade de pessoas que estão supostamente expostas a um agente etiológico, mas não necessariamente doentes (Ladeia et al., 2020; Ferreira et al., 2021). As consequências adversas desse processo têm sido amplamente previstas, pois, além das alterações econômicas e sociais, do medo do desconhecido e até mesmo da morte, o próprio confinamento prolongado está evidentemente relacionado a danos psicológicos, visto que os indivíduos estão submetidos a estressores por um longo período de tempo (Silva et al., 2021; Suryavanshi et al., 2020).

A definição de qualidade de vida engloba variados setores da vida do indivíduo, como por exemplo: social, medico, biológico, dentre outros. Dessa forma, não há unanimidade em conceituar esse termo e os estudos sobre a área ainda estão em processo de sedimentação. Na atualidade, as definições mais aceitas estão relacionadas justamente com o âmbito multidisciplinar (Almeida et al., 2012). De acordo com a Organização Mundial da Saúde, qualidade de vida é reflexo da percepção individual de cada pessoa sobre a realização ou não de suas necessidades, almejando felicidade e auto-realização (Organización Mundial de la Salud, 1998).

Corroborando o contexto pandêmico, o alto poder contaminante, o isolamento social, o medo na redução da renda financeira e os números de mortes divulgados têm sido responsáveis por sintomas de ansiedade, depressão e estresse relatados pela população, resultando em diminuição da sua qualidade de vida, com efeitos colaterais relacionados à sua saúde mental. O quadro ocorre especialmente em grupos vulneráveis e infectados pelo vírus, com impacto negativo no controle das suas comorbidades clínicas, em razão de incapacidades físicas, cognitivas e mentais associadas ao temor da doença (Ladeia et al., 2020; Mota et al., 2021). 
Destarte, o isolamento social derivado do Covid-19 desencadeou o agravamento dos quadros de pessoas que já se encontravam afetadas por doenças mentais (Garratt et al., 2021). Indivíudos que não possuíam antecedentes desenvolveram uma série de transtornos de grande importância clínica, gerando prejuízo funcional nas atividades cotidianas (Castro et al., 2021; Alves et al., 2021). Sobreviventes de outras doenças epidêmicas, como a Síndrome Respiratória do Oriente Médio (MERS) e Influenza H1N1, tiveram, e ainda têm, problemas na qualidade de vida que variam de curto a longo prazo (Guo et al., 2020).

Ademais, as repercussões causadas pela pandemia estão levando ao colapso do serviço de saúde de diversas nações, inclusive do Brasil. A pandemia ocasionada pelo Covid -19 está sendo caracterizada como um dos maiores problemas de saúde pública internacional das últimas décadas (Coronavirus disease - World Health Organization, 2020). Segundo o Departamento de Psicologia do Reino Unido, o impacto da pandemia na saúde mental ocorre não somente devido às restrições do governo e medo da doença, bem como por uma carga geral sobre os sistemas de saúde, perturbando o acesso das pessoas que necessitam de acompanhamento à saúde mental, demonstrando um déficit de 55\% dos cuidados ao paciente pela dificuldade de acesso aos serviços primários (He et al., 2021). Isso demonstra as consequências a longo prazo do Covid-19, por deixar esses serviços sobrecarregados e exacerbar o quadro desses pacientes. Diante disso, diversos aspectos podem ser atribuídos à ascensão desses transtornos, a saber: o desemprego, gerado pelas repercussões socioeconômicas da pandemia, a disseminação de notícias falsas e precoces, sobrecarga de informações, falta de acompanhamento e tratamento psicológico eficientes (Dias et al., 2021).

O Brasil tem dificuldade em avaliar o impacto do Covid-19 na sua população, por ser um país continental com regiões de cultura distinta e acentuada disparidade social, baixos níveis de educação e precária assistência à saúde. As medidas preventivas de saúde pública devem estar atentas não só aos danos da saúde física, mas também à possibilidade de doença mental (Lima et al., 2020). Evidenciar as doenças mentais e desordens psicológicas provocadas pela pandemia do novo coronavírus abre portas para a criação de políticas públicas de atenção psicossocial que promovam o bem-estar das pessoas em situação de isolamento social. Além disso, permitem uma visão holística do paciente, com cuidados que se estendem além da saúde física, contemplando as questões mentais do ser humano e toda a complexidade psicológica permeada pela pandemia (Castro et al., 2021).

\section{Metodologia}

Trata-se de estudo transversal e observacional realizado entre os meses de janeiro e agosto de 2021. Foram estudados 221 pacientes com síndrome gripal atendidos no Centro de Doença Respiratória (CDR), vinculado ao Instituto de Promoção e de Assistência à Saúde de Servidores do Estado de Sergipe - IPESAÚDE, em Aracaju, Sergipe. Os pacientes elegíveis para monitoramento remoto foram incluídos pela equipe presencial e inseridos na plataforma digital denominada "Monitora Corona".

Esses pacientes foram monitorados por acadêmicos do curso de Medicina integrantes de três universidades do Estado de Sergipe - Universidade Federal de Sergipe (Campus São Cristovão e Campus Lagarto) e Universidade Tiradentes - sob supervisão de médicos integrantes dessas Instituições. Foram coletados dados acerca da evolução do quadro, tratamento e pósalta. Pacientes elegíveis para monitoramento remoto foram incluídos pela equipe presencial e inseridos na plataforma e englobaram: sintomas clínicos caraterísticos da síndrome gripal, história de contato com pessoas com o Covid-19 e que ainda estavam na janela de transmissão da doença. Para aplicação do questionário, em um segundo momento da pesquisa, foram selecionados aqueles com RT-PCR positivo, incluídos na plataforma. Foram excluídos do estudo os óbitos, pacientes com RT- 
PCR negativo para o Covid-19, crianças (<12 anos) e aqueles que não concordaram com o Termo de Consentimento Livre e Esclarecido ou Termo de Anuência Livre e Esclarecida.

O aplicativo "Monitora Corona" era híbrido, ou seja, funcionava em navegadores de internet, por meio de computadores ou smartphones. Para a elaboração do aplicativo, foram utilizadas técnicas de programação, tais como Java Script, React, SQL, entre outras. A experiência do usuário foi dividida em duas interfaces: experiência do paciente e do profissional de saúde. Na interface da aba paciente, podiam ser cadastrados todos os membros da família na mesma conta, a Unidade Básica de Saúde (UBS) de referência e registro dos dados socioeconômicos. Na interface dos profissionais de saúde havia opções para Unidades de Saúde, estudante ou médico que prestou teleatendimento e Secretaria Municipal de Saúde com funções específicas.

A pesquisa utilizou os dados sociodemográficos contidos na plataforma perante assinatura de ofício pela coordenação do IPES, e os dados telefônicos contidos no mesmo foram utilizados para contactar pacientes via ligação telefônica ou Whatsapp, em um segundo momento, para aplicação do questionário SF-36. Os dados sociodemográficos constados na plataforma foram: nome do paciente, idade, sexo, cor/raça, procedência, escolaridade, estado civil, setor da profissão, profissional de saúde, vacinação da gripe, comorbidades presentes (hipertensão arterial sistêmica, diabetes mellitus, obesidade, tabagismo e carga tabágica, infarto agudo do miocárdio, doença pulmonar obstrutiva crônica, asma, neoplasia ativa, doença renal crônica, etilismo, dislipdemia e doenças psiquiátricas), sintomas relatados ao longo da doença (tosse seca, tosse produtiva, dispneia, febre, odinofagia, disgeusia, anosmia, diarreia, dor abdominal, hiporexia, mialgia, astenia, artralgia, cefaleia, náuseas/vômitos, espirro/coriza, tontura, confusão mental e lesões de pele), realização de RT-PCR e sorologia (IgM e IgG) para diagnóstico do Covid-19, realização de tomografia computadorizada, necessidade de internação hospitalar em Unidade de Terapia Intensiva (UTI), uso de oxigenoterapia e/ou intubação orotraqueal, uso de antibioticoterapia, ivermectina, doxicilina, tamiflu, corticoide, heparina e hidroxicloroquina, tipagem sanguínea e desfecho (vida ou morte).

Utilizou-se o questionário SF-36 específico para avaliação da qualidade de vida. O SF-36 é um instrumento de qualidade de vida multidimensional que foi desenvolvido em 1992 por Ware e Sherbourne e validado no Brasil por Ciconelli et al em 1999. O questionário é composto por trinta e seis itens, agrupados em oitos dimensões: capacidade funcional (dez itens), aspectos físicos (quatro itens), dor (dois itens), estado geral de saúde (cinco itens), vitalidade (quatro itens), aspectos sociais (dois itens), aspectos emocionais (três itens), saúde mental (cinco itens). Para cada paciente e para cada uma das oito dimensões obteve-se um escore ao se aplicar uma escala de medida com valores de 0 (mais comprometido) a 100 (nenhum comprometimento), avaliando tanto os aspectos negativos da saúde (doença ou enfermidade) como os aspectos positivos (saúde e bem estar). (Silva et al., 2021; M. d. Castro et al., 2003; Laguardia et al., 2013).

As variáveis categóricas foram descritas por meio de frequência absoluta e relativa percentual. As variáveis contínuas foram descritas por meio de média, mediana, desvio padrão e intervalo interquartil. O teste de Shapiro-Wilks foi utilizado para avaliar a hipótese de aderência das variáveis contínuas a distribuição normal. Como foi rejeitada, foi utilizado o Teste de Kruskal-Wallis para avaliar a hipótese de igualdade de medianas independentes. Para a hipótese de igualdade das medianas dois a dois foi aplicado o teste de Kruskal-Wallis-Dunn. A hipótese de ausência de correlação entre variáveis contínuas/discretas foi medida e testada por meio da correlação de Spearman. O nível de significância adotado em todo o estudo foi de 0,05 e o software utilizado foi o R Core Team 2021 (Versão 4.1.0) (Hanusz \& Tarasinska, 2016; Lou \& Yuen, 2018; Dinno, 2015).

As informações foram apresentadas de forma coletiva, sem qualquer possibilidade de identificação individual. A confidencialidade dos resultados obtidos foi garantida a todos os pacientes que concordaram com o Termo de Consentimento Livre e Esclarecido, e, no caso dos estudantes com menos de 18 anos, houve concordância do Termo de Anuência Livre e 
Research, Society and Development, v. 10, n. 14, e219101421769, 2021

(CC BY 4.0) | ISSN 2525-3409 | DOI: http://dx.doi.org/10.33448/rsd-v10i14.21769

Esclarecida, assinada pelos jovens e pelos responsáveis dos mesmos, garantindo o anonimato e a possibilidade de retirar seu consentimento a qualquer momento, sem quaisquer tipos de prejuízos.

O estudo foi conduzido de acordo com os princípios éticos e orientações contidas na Resolução $\mathrm{n}^{\circ} 466$, de 12 de dezembro de 2012. O projeto foi submetido e aprovado no Comitê de Ética em Pesquisa da Universidade Tiradentes (CAAE: 37320120.5.0000.5371).

\section{Resultados}

Um total de 221 pacientes com RT-PCR positivo para o Covid-19 foram incluídos. Destes, 63,8\% eram do sexo feminino, com idade média de 43,6 anos e 56,6\% da raça parda, casados (55,7\%), provenientes de Aracaju - Sergipe (63,8\%). Do total de pacientes, 46,2\% são da área da saúde (Tabela 1)

Tabela 1: Perfil sociodemográfico dos pacientes. Aracaju, SE, 2021.

\begin{tabular}{|c|c|c|}
\hline & $\mathrm{N}$ & $\%$ \\
\hline \multicolumn{3}{|l|}{ Sexo } \\
\hline Feminino & 141 & 63,8 \\
\hline Masculino & 80 & 36,2 \\
\hline \multicolumn{3}{|l|}{ Cor/raça } \\
\hline Branca & 40 & 18,1 \\
\hline Parda & 125 & 56,6 \\
\hline Negra & 31 & 14,0 \\
\hline Amarela & 3 & 1,4 \\
\hline Não informada & 22 & 10,0 \\
\hline \multicolumn{3}{|l|}{ Procedencia } \\
\hline Aracaju & 141 & 63,8 \\
\hline Socorro & 22 & 10,0 \\
\hline São Cristóvão & 10 & 4,5 \\
\hline Outros Sergipe & 25 & 11,3 \\
\hline Outros Estados & 2 & ,9 \\
\hline Não informado & 21 & 9,5 \\
\hline \multicolumn{3}{|l|}{ Estado Civil } \\
\hline Casado(a) & 123 & 55,7 \\
\hline Solteiro(a) & 54 & 24,4 \\
\hline Separado(a) & 27 & 12,2 \\
\hline Viúvo(a) & 1 &, 5 \\
\hline União Estável & 16 & 7,2 \\
\hline \multicolumn{3}{|l|}{ Setor Profissão } \\
\hline Aposentado(a) & 20 & 9,0 \\
\hline Comércio e Indústria & 16 & 7,2 \\
\hline Desempregado(a) & 4 & 1,8 \\
\hline Educação & 18 & 8,1 \\
\hline Estudante & 7 & 3,2 \\
\hline Financeiro & 5 & 2,3 \\
\hline
\end{tabular}


Research, Society and Development, v. 10, n. 14, e219101421769, 2021

(CC BY 4.0) | ISSN 2525-3409 | DOI: http://dx.doi.org/10.33448/rsd-v10i14.21769

\begin{tabular}{lll} 
Justiça & 4 & 1,8 \\
Saúde & 102 & 46,2 \\
Segurança & 33 & 14,9 \\
Não informado & 12 & 5,4 \\
\hline
\end{tabular}

Legenda: $\mathrm{n}$ - frequência absoluta. \% - frequência relativa percentual. Fonte: Autores.

As comorbidades mais prevalentes foram hipertensão arterial sistêmica $(28,1 \%)$, obesidade $(27,6 \%)$ e antecedentes de doenças psiquiátricas (10\%) (Tabela 2). No âmbito dos sintomas que mais acometeram os pacientes, 79,2\% relataram cefaleia, $65,6 \%$ astenia, $53,8 \%$ mialgia, $55,2 \%$ disgeusia, $48 \%$ diarreia, $44,8 \%$ anosmia, $42,1 \%$ odinofagia, $36,7 \%$ dispneia e $35,3 \%$ febre, ao longo do curso da doença. Apenas 5 pacientes $(2,3 \%)$ necessitaram de internação hospitalar e destes, dois fizeram uso de oxigenioterapia. $67 \%$ da amostra fez uso de antibioticoterapia.

Tabela 2: Comorbidades associadas aos participantes da pesquisa. Aracaju, SE, 2021.

\begin{tabular}{|c|c|c|}
\hline & $\mathrm{n}$ & $\%$ \\
\hline \multicolumn{3}{|c|}{ Hipertensão arterial sistêmica (HAS) } \\
\hline Sim & 62 & 28,1 \\
\hline Não & 159 & 71,9 \\
\hline \multicolumn{3}{|c|}{ Diabetes mellitus (DM) } \\
\hline Sim & 16 & 7,2 \\
\hline Não & 205 & 92,8 \\
\hline \multicolumn{3}{|l|}{ Obesidade } \\
\hline Sim & 61 & 27,6 \\
\hline Não & 160 & 72,4 \\
\hline \multicolumn{3}{|l|}{ Tabagismo } \\
\hline Sim & 1 & 0,5 \\
\hline Não & 220 & 99,5 \\
\hline \multicolumn{3}{|l|}{ Asma } \\
\hline Sim & 6 & 2,7 \\
\hline Não & 215 & 97,3 \\
\hline \multicolumn{3}{|c|}{ Índice de Massa Corpórea (IMC) } \\
\hline$<18,5$ & 3 & 1,4 \\
\hline $18,5-24,9$ & 64 & 29,0 \\
\hline $25-29,9$ & 80 & 36,2 \\
\hline $30-39,9$ & 55 & 24,9 \\
\hline$>40$ & 3 & 1,4 \\
\hline Não informado & 16 & 7,2 \\
\hline \multicolumn{3}{|l|}{ Neoplasia Ativa } \\
\hline Sim & 1 & 0,5 \\
\hline Não & 220 & 99,5 \\
\hline \multicolumn{3}{|l|}{ Etilismo } \\
\hline Sim & 40 & 18,1 \\
\hline Não & 181 & 81,9 \\
\hline
\end{tabular}


Research, Society and Development, v. 10, n. 14, e219101421769, 2021

(CC BY 4.0) | ISSN 2525-3409 | DOI: http://dx.doi.org/10.33448/rsd-v10i14.21769

\begin{tabular}{lll} 
Dislipidemia & & \\
Sim & 16 & 7,2 \\
Não & 205 & 92,8 \\
Doenças Psiquiátricas & & \\
Sim & 22 & 10,0 \\
Não & 199 & 90,0 \\
\hline
\end{tabular}

Legenda: $\mathrm{n}$ - frequência absoluta. \% - frequência relativa percentual. Fonte: Autores.

A Tabela 3 mostra os valores obtidos de média e mediana para cada domínio do questionário SF-36. Demonstrou-se que a capacidade funcional média dos participantes foi de 68,5 DP, estando mais próximo do limite superior. Destarte, limitação por aspectos físicos (48,9 DP) e limitação por aspectos emocionais (43,4 DP), mais próximos do limite inferior. Não houve diferenças significativas entre o sexo dos indivíduos nos diferentes domínios.

Tabela 3: Domínios analisados pelo SF-36. Aracaju, SE, 2021.

\begin{tabular}{lll}
\hline & Média (DP) & Mediana (IIQ) \\
\hline Capacidade funcional & $68,5(27,1)$ & $70(50-95)$ \\
Limitação por aspectos físicos & $48,9(43)$ & $50(0-100)$ \\
Dor & $55,5(21,3)$ & $50(40-70)$ \\
Estado geral de saúde & $54,9(19,4)$ & $50(40-70)$ \\
Vitalidade & $50,5(14,9)$ & $50(40-65)$ \\
Aspectos sociais & $53,5(25,5)$ & $50(37,5-75)$ \\
Limitação por aspectos emocionais & $43,4(43,9)$ & $33,3(0-100)$ \\
Saúde mental & $54,3(22,3)$ & $52(36-72)$ \\
\hline
\end{tabular}

Legenda: DP - Desvio Padrão. IIQ - Intervalo Interquartil. Fonte: Autores.

A Tabela 4 demonstra as variáveis dos dados analisados referente a cada domínio do questionário SF-26, individualmente. Analisando-se o primeiro domínio, aposentadoria (50,8 DP), trabalhadores do setor da justiça (32,5 DP) e necessidade de oxigenioterapia $(32,5 \mathrm{DP})$ foram fatores significativos, associados a uma pontuação baixa em Capacidade Funcional. Demonstrou-se que os sintomas presentes durante o curso da doença não afetaram o indivíduo no período pós Covid-19. 
Research, Society and Development, v. 10, n. 14, e219101421769, 2021

(CC BY 4.0) | ISSN 2525-3409 | DOI: http://dx.doi.org/10.33448/rsd-v10i14.21769

Tabela 4: Variáveis referente a cada domínio do questionário SF-36. Aracaju, SE, 2021.

\begin{tabular}{|c|c|c|c|c|c|c|}
\hline & \multicolumn{2}{|c|}{ Capacidade Funcional } & \multirow[b]{2}{*}{ p-valor } & \multicolumn{2}{|c|}{$\begin{array}{c}\text { Limitação por aspectos } \\
\text { físicos } \\
\end{array}$} & \multirow[b]{2}{*}{$\mathrm{p}$-valor } \\
\hline & Média (DP) & Mediana (IIQ) & & Média (DP) & Mediana (IIQ) & \\
\hline \multicolumn{7}{|l|}{ Sexo } \\
\hline Feminino & $67,8(27,6)$ & $70(50-95)$ & \multirow[t]{2}{*}{0,670} & $49,4(42,3)$ & $50(0-100)$ & \multirow[t]{2}{*}{0,766} \\
\hline Masculino & $69,9(26,4)$ & $72,5(50-95)$ & & $47,9(44,6)$ & $50(0-100)$ & \\
\hline \multicolumn{7}{|l|}{ Cor/raça } \\
\hline Branca & $67,9(25,1)$ & $70(50-90)$ & \multirow[t]{5}{*}{0,224} & $39,5(40,9)$ & $25(0-75)$ & \multirow[t]{5}{*}{0,202} \\
\hline Parda & $68,2(27,2)$ & $70(50-95)$ & & $47(42,8)$ & $50(0-100)$ & \\
\hline Negra & $76,1(29,7)$ & $90(52,5-100)$ & & $60,2(43,4)$ & $75(12,5-100)$ & \\
\hline Amarela & $63,3(27,5)$ & $50(47,5-72,5)$ & & $50(50)$ & $50(25-75)$ & \\
\hline Não informada & $59,7(27,2)$ & $50(42,5-85)$ & & $66,7(44)$ & $100(25-100)$ & \\
\hline \multicolumn{7}{|l|}{ Procedência } \\
\hline Aracaju & $68,6(27,3)$ & $70(50-95)$ & \multirow[t]{6}{*}{0,189} & $45,2(42,6)$ & $50(0-100)$ & \multirow[t]{6}{*}{0,080} \\
\hline Socorro & $64,5(26,5)$ & $65(45-85)$ & & $45,2(43)$ & $50(0-100)$ & \\
\hline São Cristóvão & $80(26,2)$ & $90(60-100)$ & & $75(37,3)$ & $100(50-100)$ & \\
\hline Outros Sergipe & $74(28,2)$ & $80(60-100)$ & & $56,3(42,5)$ & $50(12,5-100)$ & \\
\hline Outros Estados & $65(7,1)$ & $65(60-70)$ & & * & $*$ & \\
\hline Não informado & $56,8(25,7)$ & $50(40-80)$ & & $64,3(44,6)$ & $87,5(0-100)$ & \\
\hline \multicolumn{7}{|l|}{ Escolaridade } \\
\hline EFI & $60(14,1)$ & $60(50-70)$ & \multirow[t]{6}{*}{0,151} & $87,5(17,7)$ & $87,5(75-100)$ & \multirow[t]{6}{*}{0,676} \\
\hline $\mathrm{EFC}$ & $58(25,1)$ & $50(45-60)$ & & $35(48,7)$ & $0(0-75)$ & \\
\hline EMI & $80(24,5)$ & $90(50-100)$ & & $37,5(37,9)$ & $37,5(0-50)$ & \\
\hline EMC & $68,5(25,5)$ & $70(50-90)$ & & $47,5(43,2)$ & $50(0-100)$ & \\
\hline ES & $70,6(28,9)$ & $80(50-100)$ & & $48,9(42,8)$ & $50(0-100)$ & \\
\hline Não informado & $55,7(25,1)$ & $50(40-67,5)$ & & $60(46,1)$ & $75(0-100)$ & \\
\hline \multicolumn{7}{|l|}{ Estado Civil } \\
\hline Casado & $68,2(27,1)$ & $70(50-95)$ & \multirow[t]{4}{*}{0,501} & $47,8(42,5)$ & $50(0-100)$ & 0,294 \\
\hline Solteiro & $70,4(28)$ & $75(50-100)$ & & $51,5(44,4)$ & $50(0-100)$ & \\
\hline Separado & $65,6(26,8)$ & $67,5(47,5-90)$ & & $41,7(43,4)$ & $25(0-100)$ & \\
\hline União Estável & $73,6(24,3)$ & $75(52,5-95)$ & & $68,2(38,9)$ & $100(37,5-100)$ & \\
\hline Setor Profissão & & & & & & \\
\hline Aposentado & $50,8(18,2)$ & $50(45-60)$ & 0,025 & $43,4(41,5)$ & $25(0-75)$ & 0,295 \\
\hline Comércio e Indústria & $75(26,6)$ & $87,5(55-95)$ & & $59,4(40,7)$ & $62,5(25-100)$ & \\
\hline Desempregado & $85(17,8)$ & $90(72,5-97,5)$ & & $68,8(37,5)$ & $75(37,5-100)$ & \\
\hline Educação & $79(26,4)$ & $90(67,5-100)$ & & $61,7(42,1)$ & $75(25-100)$ & \\
\hline Estudante & $72,5(25,6)$ & $70(60-100)$ & & $20,8(24,6)$ & $12,5(0-50)$ & \\
\hline Financeiro & $74(35,6)$ & $100(35-100)$ & & $65(48,7)$ & $100(25-100)$ & \\
\hline Justiça & $32,5(24,7)$ & $32,5(15-50)$ & & * & $*$ & \\
\hline Saúde & $67,9(28,6)$ & $70(50-97,5)$ & & $48,9(44)$ & $50(0-100)$ & \\
\hline Segurança & $73,8(22,2)$ & $77,5(60-95)$ & & $48,3(41,5)$ & $50(0-100)$ & \\
\hline Não informado & $61,4(28,2)$ & $60(47,5-77,5)$ & & $36,4(50,5)$ & $0(0-100)$ & \\
\hline Vacinação da Gripe & & & & & & \\
\hline Sim & $67,2(27,7)$ & $65(45-95)$ & 0,280 & $50,4(43)$ & $50(0-100)$ & 0,312 \\
\hline Não & $70,9(25,8)$ & $77,5(50-90)$ & & $44,8(43)$ & $50(0-100)$ & \\
\hline Não Informado & $*$ & $*$ & & * & $*$ & \\
\hline HAS & & & & & & \\
\hline Sim & $67(26,7)$ & $70(50-87,5)$ & 0,506 & $47,5(43,7)$ & $50(0-100)$ & 0,749 \\
\hline Não & $69,1(27,4)$ & $70(50-95)$ & & $49,5(42,8)$ & $50(0-100)$ & \\
\hline $\mathrm{DM}$ & & & & & & \\
\hline Sim & $65,3(34,4)$ & $75(32,5-100)$ & 0,942 & $50(43,8)$ & $50(0-100)$ & 0,850 \\
\hline Não & $68,8(26,5)$ & $70(50-95)$ & & $48,8(43)$ & $50(0-100)$ & \\
\hline Obeso & & & & & & \\
\hline Sim & $69,5(27,3)$ & $70(50-100)$ & 0,751 & $53,4(43,5)$ & $50(0-100)$ & 0,360 \\
\hline Não & $68,1(27,2)$ & $70(50-95)$ & & $47(42,8)$ & $50(0-100)$ & \\
\hline Asma & & & & & & \\
\hline
\end{tabular}


Research, Society and Development, v. 10, n. 14, e219101421769, 2021

(CC BY 4.0) | ISSN 2525-3409 | DOI: http://dx.doi.org/10.33448/rsd-v10i14.21769

\begin{tabular}{ccccccc}
\hline Sim & $76,7(19,7)$ & $80(60-90)$ & 0,528 & $50(47,4)$ & $50(0-100)$ & 0,967 \\
Não & $68,2(27,3)$ & $70(50-95)$ & & $48,8(43)$ & $50(0-100)$ & \\
IMC & & & & & & \\
$<18,5$ & $87,5(10,6)$ & $87,5(80-95)$ & 0,612 & $75(35,4)$ & $75(50-100)$ & 0,734 \\
$18,5-24,9$ & $67,7(30)$ & $70(50-100)$ & & $45(43,1)$ & $37,5(0-100)$ & \\
$25-29,9$ & $65,9(26,3)$ & $67,5(50-90)$ & & $45,8(42,8)$ & $37,5(0-100)$ & \\
$30-39,9$ & $70,4(26,7)$ & $70(50-100)$ & & $55,8(43,6)$ & $50(0-100)$ & \\
$>40$ & $90(8,7)$ & $85(85-92,5)$ & & $50(50)$ & $50(25-75)$ & \\
Não informado & $71,8(21,2)$ & $70(55-87,5)$ & & $52,3(44)$ & $75(0-87,5)$ & \\
Etilismo & & & & & & \\
Sim & $61,3(32)$ & $60(42,5-90)$ & 0,427 & $45,3(44,6)$ & $37,5(0-100)$ & 0,615 \\
Não & $69,9(26)$ & $70(50-95)$ & & $49,6(42,8)$ & $50(0-100)$ & \\
Dislipidemia & & & & & & \\
Sim & $65,3(24,3)$ & $52,5(47,5-92,5)$ & 0,192 & $48,4(46,1)$ & $37,5(0-100)$ & 0,968 \\
Não & $68,8(27,4)$ & $70(50-95)$ & & $48,9(42,9)$ & $50(0-100)$ & \\
Sim & $65,3(24,5)$ & $60(50-90)$ & 0,410 & $50(41,1)$ & $37,5(25-100)$ & 0,770 \\
Não & $68,8(27,4)$ & $70(50-95)$ & & $48,8(43,3)$ & $50(0-100)$ \\
\hline
\end{tabular}

\begin{tabular}{|c|c|c|c|c|c|c|}
\hline & \multicolumn{2}{|c|}{ Dor } & \multirow[b]{2}{*}{$\mathrm{p}$-valor } & \multicolumn{2}{|c|}{ Estado geral de saúde } & \multirow[b]{2}{*}{$\mathrm{p}$-valor } \\
\hline & Média (DP) & Mediana (IIQ) & & Média (DP) & Mediana (IIQ) & \\
\hline \multicolumn{7}{|l|}{ Sexo } \\
\hline Feminino & $55(20,7)$ & $50(40-70)$ & \multirow[t]{2}{*}{0,805} & $55(18)$ & $50(45-70)$ & \multirow[t]{2}{*}{0,709} \\
\hline Masculino & $56,4(22,6)$ & $50(40-80)$ & & $54,6(21,8)$ & $52,5(40-70)$ & \\
\hline \multicolumn{7}{|l|}{ Cor/raça } \\
\hline Branca & $54,6(19,8)$ & $50(40-70)$ & \multirow[t]{5}{*}{0,228} & $54,7(20,9)$ & $50(35-70)$ & \multirow[t]{5}{*}{0,928} \\
\hline Parda & $55(20,9)$ & $50(40-70)$ & & $55,3(19,4)$ & $55(40-70)$ & \\
\hline Negra & $61,1(22,8)$ & $60(40-90)$ & & $54,1(18,8)$ & $55(40-62,5)$ & \\
\hline Amarela & $73,3(20,8)$ & $80(65-85)$ & & $45(15)$ & $45(37,5-52,5)$ & \\
\hline Não informada & $50,5(23,8)$ & $40(40-70)$ & & $55,3(18,9)$ & $50(42,5-72,5)$ & \\
\hline \multicolumn{7}{|l|}{ Procedência } \\
\hline Aracaju & $55,6(20,8)$ & $50(40-70)$ & \multirow[t]{6}{*}{0,101} & $53,7(18,1)$ & $50(40-70)$ & \multirow[t]{6}{*}{0,641} \\
\hline Socorro & $52,9(21,5)$ & $50(40-60)$ & & $56,7(21,2)$ & $50(45-75)$ & \\
\hline São Cristóvão & $68(21,5)$ & $65(50-90)$ & & $63(19,3)$ & $62,5(50-75)$ & \\
\hline Outros Sergipe & $59,6(21,4)$ & $60(40-80)$ & & $57,5(25,3)$ & $55(37,5-77,5)$ & \\
\hline Outros Estados & $35(7,1)$ & $35(30-40)$ & & $47,5(3,5)$ & $47,5(45-50)$ & \\
\hline Não informado & $49(23,4)$ & $40(40-70)$ & & $53,6(18,3)$ & $50(40-70)$ & \\
\hline \multicolumn{7}{|l|}{ Escolaridade } \\
\hline EFI & $60(14,1)$ & $60(50-70)$ & \multirow[t]{6}{*}{0,598} & $57,5(10,6)$ & $57,5(50-65)$ & \multirow[t]{6}{*}{0,991} \\
\hline $\mathrm{EFC}$ & $58(23,9)$ & $60(40-70)$ & & $55(18,4)$ & $55(55-70)$ & \\
\hline EMI & $60(17,9)$ & $55(50-70)$ & & $50,8(13,9)$ & $52,5(50-60)$ & \\
\hline EMC & $55,7(20,9)$ & $50(40-70)$ & & $54,4(22,3)$ & $55(37,5-70)$ & \\
\hline ES & $56,4(21,7)$ & $50(40-70)$ & & $55,8(17,7)$ & $50(40-70)$ & \\
\hline Não informado & $48,6(22,9)$ & $40(40-70)$ & & $53,3(17,7)$ & $50(42,5-62,5)$ & \\
\hline \multicolumn{7}{|l|}{ Estado Civil } \\
\hline Casado & $55,8(21,2)$ & $60(40-70)$ & \multirow[t]{4}{*}{0,483} & $57,2(18,7)$ & $55(45-70)$ & \multirow[t]{4}{*}{0,082} \\
\hline Solteiro & $56,7(21,8)$ & $50(40-70)$ & & $49,6(20,1)$ & $50(35-60)$ & \\
\hline Separado & $55,4(22,5)$ & $50(40-70)$ & & $54(18,1)$ & $52,5(40-67,5)$ & \\
\hline União Estável & $51,3(19,6)$ & $45(40-65)$ & & $59,1(21,8)$ & $70(42,5-75)$ & \\
\hline \multicolumn{7}{|l|}{ Setor Profissão } \\
\hline Aposentado & $50,5(17,3)$ & $50(40-70)$ & \multirow[t]{6}{*}{0,800} & $53,7(19,5)$ & $50(42,5-60)$ & \multirow[t]{6}{*}{0,507} \\
\hline Comércio e Indústria & $60(19,7)$ & $60(40-80)$ & & $57,8(18,9)$ & $60(40-70)$ & \\
\hline Desempregado & $62,5(17,1)$ & $65(50-75)$ & & $66,3(20,6)$ & $70(50-82,5)$ & \\
\hline Educação & $58,3(20,7)$ & $55(40-70)$ & & $63,3(20)$ & $70(50-80)$ & \\
\hline Estudante & $48,6(13,5)$ & $50(40-55)$ & & $41,7(20,4)$ & $37,5(25-50)$ & \\
\hline Financeiro & $50(12,2)$ & $50(50-60)$ & & $55(20,9)$ & $60(45-65)$ & \\
\hline
\end{tabular}


Research, Society and Development, v. 10, n. 14, e219101421769, 2021

(CC BY 4.0) | ISSN 2525-3409 | DOI: http://dx.doi.org/10.33448/rsd-v10i14.21769

\begin{tabular}{|c|c|c|c|c|c|c|}
\hline Justiça & $42,5(5)$ & $40(40-45)$ & & $45(7,1)$ & $45(40-50)$ & \\
\hline Saúde & $55,6(23,1)$ & $50(40-70)$ & & $54,3(18,3)$ & $55(40-70)$ & \\
\hline Segurança & $58,4(23,7)$ & $50(40-85)$ & & $53,8(23)$ & $50(40-75)$ & \\
\hline Não informado & $53,3(20,6)$ & $50(35-70)$ & & $53,6(16,7)$ & $55(42,5-60)$ & \\
\hline \multicolumn{7}{|l|}{ Vacinação da Gripe } \\
\hline Sim & $56,1(21,9)$ & $50(40-70)$ & \multirow[t]{3}{*}{0,830} & $54,1(20,3)$ & $50(40-70)$ & \multirow[t]{3}{*}{0,326} \\
\hline Não & $54(20,2)$ & $50(40-70)$ & & $56,2(16,9)$ & $55(45-70)$ & \\
\hline Não Informado & $60(28,3)$ & $60(40-80)$ & & * & * & \\
\hline \multicolumn{7}{|l|}{ HAS } \\
\hline Sim & $53,4(19,7)$ & $50(40-70)$ & \multirow[t]{2}{*}{0,447} & $54,8(18,8)$ & $50(40-70)$ & \multirow[t]{2}{*}{0,972} \\
\hline Não & $56,3(22)$ & $50(40-70)$ & & $54,9(19,6)$ & $50(40-70)$ & \\
\hline \multicolumn{7}{|l|}{ DM } \\
\hline Sim & $57,3(26,6)$ & $60(35-85)$ & \multirow[t]{2}{*}{0,826} & $50,6(20,6)$ & $45(32,5-65)$ & \multirow[t]{2}{*}{0,332} \\
\hline Não & $55,4(21)$ & $50(40-70)$ & & $55,2(19,3)$ & $52,5(40-70)$ & \\
\hline \multicolumn{7}{|l|}{ Obeso } \\
\hline Sim & $58(22,8)$ & $60(40-75)$ & \multirow[t]{2}{*}{0,302} & $55,8(17,3)$ & $55(45-70)$ & \multirow[t]{2}{*}{0,382} \\
\hline Não & $54,5(20,8)$ & $50(40-70)$ & & $54,5(20,2)$ & $50(40-70)$ & \\
\hline \multicolumn{7}{|l|}{ Asma } \\
\hline Sim & $53,3(15,1)$ & $60(40-60)$ & \multirow[t]{2}{*}{0,863} & $55(21,2)$ & $57,5(40-75)$ & \multirow[t]{2}{*}{1,000} \\
\hline Não & $55,6(21,5)$ & $50(40-70)$ & & $54,9(19,4)$ & $50(40-70)$ & \\
\hline \multicolumn{7}{|l|}{ IMC } \\
\hline$<18,5$ & $60(20)$ & $60(50-70)$ & \multirow[t]{6}{*}{0,474} & $50(28,3)$ & $50(30-70)$ & \multirow[t]{6}{*}{0,725} \\
\hline $18,5-24,9$ & $55,7(21,9)$ & $50(40-70)$ & & $52,3(19,2)$ & $50(40-60)$ & \\
\hline $25-29,9$ & $54(20,9)$ & $50(40-70)$ & & $55,6(21,5)$ & $50(40-72,5)$ & \\
\hline $30-39,9$ & $59,3(22,4)$ & $60(40-80)$ & & $55,9(17,1)$ & $55(47,5-70)$ & \\
\hline$>40$ & $56,7(28,9)$ & $40(40-65)$ & & $55(20)$ & $55(45-65)$ & \\
\hline Não informado & $48,1(16,8)$ & $40(40-55)$ & & $60(16,1)$ & $55(50-72,5)$ & \\
\hline \multicolumn{7}{|l|}{ Etilismo } \\
\hline Sim & $56,1(22,6)$ & $50(40-70)$ & \multirow[t]{2}{*}{0,919} & $51,7(19,9)$ & $50(40-60)$ & \multirow[t]{2}{*}{0,398} \\
\hline Não & $55,4(21,1)$ & $50(40-70)$ & & $55,5(19,3)$ & $52,5(40-70)$ & \\
\hline \multicolumn{7}{|l|}{ Dislipidemia } \\
\hline Sim & $55,3(19,6)$ & $50(40-70)$ & \multirow[t]{2}{*}{0,955} & $53,1(20,6)$ & $50(40-70)$ & \multirow[t]{2}{*}{0,566} \\
\hline Não & $55,5(21,5)$ & $50(40-70)$ & & $55(19,3)$ & $55(40-70)$ & \\
\hline \multicolumn{7}{|c|}{ Doenças Psiquiátricas } \\
\hline Sim & $49,5(18,6)$ & $40(40-50)$ & \multirow[t]{2}{*}{0,151} & $56,1(22)$ & $55(50-70)$ & \multirow[t]{2}{*}{0,714} \\
\hline Não & $56,1(21,6)$ & $50(40-70)$ & & $54,8(19,1)$ & $50(40-70)$ & \\
\hline
\end{tabular}

\begin{tabular}{|c|c|c|c|c|c|c|}
\hline & \multicolumn{2}{|c|}{ Vitalidade } & \multirow[b]{2}{*}{ p-valor } & \multicolumn{2}{|c|}{ Aspectos Sociais } & \multirow[b]{2}{*}{ p-valor } \\
\hline & Média (DP) & Mediana (IIQ) & & Média (DP) & Mediana (IIQ) & \\
\hline \multicolumn{7}{|l|}{ Sexo } \\
\hline Feminino & $49,7(15,5)$ & $50(35-65)$ & \multirow[t]{2}{*}{0,359} & $54,7(25,8)$ & $50(37,5-75)$ & \multirow[t]{2}{*}{0,283} \\
\hline Masculino & $52(13,6)$ & $50(40-65)$ & & $51,4(25,1)$ & $50(31,3-68,8)$ & \\
\hline \multicolumn{7}{|l|}{ Cor/raça } \\
\hline Branca & $50,3(14,4)$ & $50(40-65)$ & \multirow[t]{5}{*}{0,472} & $53,1(31,7)$ & $50(25-81,3)$ & \multirow[t]{5}{*}{0,939} \\
\hline Parda & $50,9(14,1)$ & $50(40-60)$ & & $54,4(24,9)$ & $50(37,5-75)$ & \\
\hline Negra & $50,7(18,8)$ & $50(35-70)$ & & $52,8(23)$ & $50(37,5-68,8)$ & \\
\hline Amarela & $33,3(14,4)$ & $25(25-37,5)$ & & $54,2(19,1)$ & $50(43,8-62,5)$ & \\
\hline Não informada & $51,3(14,3)$ & $55(35-65)$ & & $50(21,8)$ & $50(25-62,5)$ & \\
\hline \multicolumn{7}{|l|}{ Procedência } \\
\hline Aracaju & $50,2(14,9)$ & $50(40-60)$ & \multirow[t]{6}{*}{0,948} & $53,5(25,1)$ & $50(37,5-75)$ & \multirow[t]{6}{*}{0,551} \\
\hline Socorro & $52,6(16,5)$ & $50(40-65)$ & & $55,1(26,1)$ & $56,3(37,5-75)$ & \\
\hline São Cristóvão & $49,5(12,3)$ & $47,5(45-60)$ & & $65(29,9)$ & $75(62,5-75)$ & \\
\hline Outros Sergipe & $50,8(16,3)$ & $50(35-65)$ & & $52,6(30,4)$ & $56,3(25-75)$ & \\
\hline Outros Estados & $57,5(10,6)$ & $57,5(50-65)$ & & $50(35,4)$ & $50(25-75)$ & \\
\hline Não informado & $50(13,9)$ & $52,5(35-65)$ & & $47,6(19,2)$ & $50(25-62,5)$ & \\
\hline
\end{tabular}


Research, Society and Development, v. 10, n. 14, e219101421769, 2021

(CC BY 4.0) | ISSN 2525-3409 | DOI: http://dx.doi.org/10.33448/rsd-v10i14.21769

\begin{tabular}{|c|c|c|c|c|c|c|}
\hline EFI & $35(14,1)$ & $35(25-45)$ & \multirow[t]{6}{*}{0,494} & $43,8(26,5)$ & $43,8(25-62,5)$ & \multirow[t]{6}{*}{0,634} \\
\hline $\mathrm{EFC}$ & $50(12,7)$ & $50(40-60)$ & & $57,5(28,8)$ & $50(37,5-87,5)$ & \\
\hline EMI & $42,5(10,4)$ & $42,5(35-45)$ & & $39,6(27,9)$ & $37,5(25-62,5)$ & \\
\hline EMC & $50,5(14,4)$ & $50(40-60)$ & & $55,3(27,9)$ & $50(37,5-75)$ & \\
\hline ES & $51,4(15,9)$ & $50(40-65)$ & & $54,3(24,6)$ & $50(37,5-75)$ & \\
\hline Não informado & $50,7(13,6)$ & $55(35-65)$ & & $47,2(18,9)$ & $50(25-62,5)$ & \\
\hline \multicolumn{7}{|l|}{ Estado Civil } \\
\hline Casado & $50,5(14,9)$ & $50(40-65)$ & \multirow[t]{4}{*}{0,634} & $53,5(24,4)$ & $50(37,5-75)$ & \multirow[t]{4}{*}{0,342} \\
\hline Solteiro & $50,6(14,9)$ & $50(40-65)$ & & $54,6(28,5)$ & $50(37,5-75)$ & \\
\hline Separado & $49,8(14,7)$ & $52,5(35-60)$ & & $53,7(25,9)$ & $50(37,5-75)$ & \\
\hline União Estável & $54,1(16,7)$ & $55(45-67,5)$ & & $46,1(21,8)$ & $43,8(25-50)$ & \\
\hline \multicolumn{7}{|l|}{ Setor Profissão } \\
\hline Aposentado & $44,2(17,1)$ & $35(35-55)$ & \multirow[t]{10}{*}{0,317} & $51,3(29,8)$ & $50(25-75)$ & \multirow[t]{10}{*}{0,273} \\
\hline Comércio e Indústria & $55,3(13,2)$ & $55(45-65)$ & & $67,2(27,7)$ & $68,8(50-87,5)$ & \\
\hline Desempregado & $61,3(4,8)$ & $62,5(57,5-65)$ & & $65,6(18,8)$ & $62,5(50-81,3)$ & \\
\hline Educação & $54,7(16,4)$ & $45(40-70)$ & & $58,8(27,5)$ & $50(37,5-75)$ & \\
\hline Estudante & $51,7(14,4)$ & $50(45-65)$ & & $39,3(31)$ & $25(18,8-68,8)$ & \\
\hline Financeiro & $46(15,6)$ & $50(35-60)$ & & $52,5(25,6)$ & $62,5(25-75)$ & \\
\hline Justiça & $40(7,1)$ & $40(35-45)$ & & $34,4(18,8)$ & $37,5(18,8-50)$ & \\
\hline Saúde & $49,8(15,2)$ & $50(37,5-65)$ & & $53,5(23,6)$ & $50(37,5-75)$ & \\
\hline Segurança & $51(12,8)$ & $50(40-60)$ & & $50,4(22,4)$ & $50(37,5-62,5)$ & \\
\hline Não informado & $53,2(15,4)$ & $50(45-65)$ & & $51(33,1)$ & $56,3(25-81,3)$ & \\
\hline \multicolumn{7}{|l|}{ Vacinação da Gripe } \\
\hline Sim & $50(15,2)$ & $50(40-60)$ & \multirow[t]{3}{*}{0,324} & $52,9(26,2)$ & $50(31,3-75)$ & \multirow[t]{3}{*}{0,542} \\
\hline Não & $51,3(14,3)$ & $50(40-65)$ & & $54,2(24)$ & $50(37,5-75)$ & \\
\hline Não Informado & $*$ & $*$ & & $75(35,4)$ & $75(50-100)$ & \\
\hline \multicolumn{7}{|l|}{ HAS } \\
\hline Sim & $51,9(13,5)$ & $50(42,5-60)$ & \multirow[t]{2}{*}{0,439} & $54,9(24,3)$ & $50(37,5-75)$ & \multirow[t]{2}{*}{0,626} \\
\hline Não & $50(15,5)$ & $50(35-65)$ & & $52,9(26,1)$ & $50(25-75)$ & \\
\hline \multicolumn{7}{|l|}{$\mathrm{DM}$} \\
\hline Sim & $51,9(14,7)$ & $50(42,5-62,5)$ & \multirow[t]{2}{*}{0,724} & $47,5(25,1)$ & $50(31,3-62,5)$ & \multirow[t]{2}{*}{0,430} \\
\hline Não & $50,4(15)$ & $50(40-65)$ & & $53,9(25,6)$ & $50(37,5-75)$ & \\
\hline \multicolumn{7}{|l|}{ Obeso } \\
\hline Sim & $50,5(13,7)$ & $50(40-60)$ & \multirow[t]{2}{*}{0,998} & $58,1(25)$ & $50(37,5-75)$ & 0,174 \\
\hline Não & $50,5(15,4)$ & $50(35-65)$ & & $51,8(25,6)$ & $50(25-75)$ & \\
\hline Asma & & & & & & \\
\hline Sim & $57,5(8,8)$ & $60(50-65)$ & 0,221 & $72,9(30)$ & $81,3(50-100)$ & 0,085 \\
\hline Não & $50,3(15)$ & $50(40-65)$ & & $52,9(25,3)$ & $50(37,5-75)$ & \\
\hline IMC & & & & & & \\
\hline$<18,5$ & $45(7,1)$ & $45(40-50)$ & 0,801 & $45,8(26)$ & $37,5(31,3-56,3)$ & 0,145 \\
\hline $18,5-24,9$ & $49,5(16)$ & $50(35-65)$ & & $53,3(22,8)$ & $50(37,5-75)$ & \\
\hline $25-29,9$ & $50,9(15,4)$ & $55(35-65)$ & & $49,2(27,4)$ & $50(25-75)$ & \\
\hline $30-39,9$ & $50,1(14,1)$ & $50(40-60)$ & & $57,8(23,8)$ & $50(37,5-75)$ & \\
\hline$>40$ & $58,3(10,4)$ & $55(52,5-62,5)$ & & $87,5(21,7)$ & $100(81,3-100)$ & \\
\hline Não informado & $54,5(11,7)$ & $60(42,5-65)$ & & $56,3(28,5)$ & $56,3(25-81,3)$ & \\
\hline Etilismo & & & & & & \\
\hline Sim & $48,9(14,6)$ & $47,5(35-60)$ & 0,387 & $53,2(26,4)$ & $50(37,5-75)$ & 0,930 \\
\hline Não & $50,8(15)$ & $50(40-65)$ & & $53,6(25,4)$ & $50(37,5-75)$ & \\
\hline Dislipidemia & & & & & & \\
\hline Sim & $53,4(15,7)$ & $55(37,5-67,5)$ & 0,469 & $57,8(26,6)$ & $50(37,5-81,3)$ & 0,592 \\
\hline Não & $50,3(14,9)$ & $50(40-65)$ & & $53,2(25,5)$ & $50(37,5-75)$ & \\
\hline Doenças Psiquiátricas & & & & & & \\
\hline Sim & $47,5(15,3)$ & $47,5(40-60)$ & 0,411 & $51,7(25,7)$ & $50(25-75)$ & 0,726 \\
\hline Não & $50,8(14,9)$ & $50(40-65)$ & & $53,7(25,6)$ & $50(37,5-75)$ & \\
\hline
\end{tabular}


Research, Society and Development, v. 10, n. 14, e219101421769, 2021

(CC BY 4.0) | ISSN 2525-3409 | DOI: http://dx.doi.org/10.33448/rsd-v10i14.21769

\begin{tabular}{|c|c|c|c|c|c|c|}
\hline & Média (DP) & Mediana (IIQ) & p-valor & Média (DP) & Mediana (IIQ) & p-valor \\
\hline \multicolumn{7}{|l|}{ Sexo } \\
\hline Feminino & $44,5(43,3)$ & $33,3(0-100)$ & \multirow[t]{2}{*}{0,590} & $52,9(22,6)$ & $50(36-72)$ & \multirow[t]{2}{*}{0,329} \\
\hline Masculino & $41,4(45,2)$ & $33,3(0-100)$ & & $56,9(21,7)$ & $56(40-76)$ & \\
\hline \multicolumn{7}{|l|}{ Cor/raça } \\
\hline Branca & $37,7(41,9)$ & $33,3(0-100)$ & \multirow[t]{5}{*}{0,410} & $55,5(26,2)$ & $56(36-76)$ & \multirow[t]{5}{*}{0,929} \\
\hline Parda & $40,8(43,8)$ & $33,3(0-100)$ & & $53,8(21,3)$ & $52(40-68)$ & \\
\hline Negra & $54,3(44,5)$ & $66,7(0-100)$ & & $54,4(21,9)$ & $48(38-74)$ & \\
\hline Amarela & $66,7(57,7)$ & $100(50-100)$ & & $44(30,2)$ & $40(28-58)$ & \\
\hline Não informada & $54,8(46,4)$ & $66,7(0-100)$ & & $56,3(21)$ & $60(38-70)$ & \\
\hline \multicolumn{7}{|l|}{ Procedência } \\
\hline Aracaju & $43,2(43,9)$ & $33,3(0-100)$ & \multirow[t]{6}{*}{0,637} & $52,6(21,4)$ & $52(40-68)$ & \multirow[t]{6}{*}{0,790} \\
\hline Socorro & $39,7(43)$ & $33,3(0-100)$ & & $57,9(24,6)$ & $60(36-84)$ & \\
\hline São Cristóvão & $56,7(44,6)$ & $66,7(0-100)$ & & $61,6(26,4)$ & $64(48-84)$ & \\
\hline Outros Sergipe & $41,7(45,3)$ & $33,3(0-100)$ & & $57(25,3)$ & $52(34-78)$ & \\
\hline Outros Estados & $*$ & $*$ & & $56(33,9)$ & $56(32-80)$ & \\
\hline Não informado & $51,3(46,4)$ & $66,7(0-100)$ & & $53,7(19,2)$ & $54(36-68)$ & \\
\hline \multicolumn{7}{|l|}{ Escolaridade } \\
\hline EFI & $50(70,7)$ & $50(0-100)$ & \multirow[t]{6}{*}{0,941} & $34(19,8)$ & $34(20-48)$ & \multirow[t]{6}{*}{0,201} \\
\hline $\mathrm{EFC}$ & $40(43,5)$ & $33,3(0-66,7)$ & & $56,8(14,3)$ & $52(48-60)$ & \\
\hline EMI & $27,8(39)$ & $16,7(0-33,3)$ & & $34(20,5)$ & $32(16-44)$ & \\
\hline EMC & $46,8(45,5)$ & $33,3(0-100)$ & & $56,7(21,9)$ & $56(40-76)$ & \\
\hline ES & $40,9(42,8)$ & $33,3(0-100)$ & & $53,9(23,2)$ & $56(36-72)$ & \\
\hline Não informado & $47,6(46,6)$ & $50(0-100)$ & & $53,6(18,5)$ & $52(38-66)$ & \\
\hline \multicolumn{7}{|l|}{ Estado Civil } \\
\hline Casado & $41,1(44,1)$ & $33,3(0-100)$ & \multirow[t]{4}{*}{0,330} & $55,1(22,9)$ & $52(36-76)$ & \multirow[t]{4}{*}{0,592} \\
\hline Solteiro & $52(43,2)$ & $50(0-100)$ & & $51(23,1)$ & $48(36-72)$ & \\
\hline Separado & $36,1(43,9)$ & $0(0-83,3)$ & & $57,3(17,5)$ & $60(46-72)$ & \\
\hline União Estável & $48,5(45,6)$ & $33,3(0-100)$ & & $55,3(22,3)$ & $60(42-64)$ & \\
\hline \multicolumn{7}{|l|}{ Setor Profissão } \\
\hline Aposentado & $36,8(41,4)$ & $33,3(0-66,7)$ & \multirow[t]{10}{*}{0,268} & $46,7(24,9)$ & $44(28-60)$ & \multirow[t]{10}{*}{0,076} \\
\hline Comércio e Indústria & $64,6(46,3)$ & $100(0-100)$ & & $67(19,2)$ & $70(48-80)$ & \\
\hline Desempregado & $66,7(47,1)$ & $83,3(33,3-100)$ & & $68(15,7)$ & $70(56-80)$ & \\
\hline Educação & $55,6(46,6)$ & $66,7(0-100)$ & & $65,6(20,2)$ & $60(48-84)$ & \\
\hline Estudante & $22,2(27,2)$ & $16,7(0-33,3)$ & & $40,7(18,1)$ & $42(32-52)$ & \\
\hline Financeiro & $60(36,5)$ & $33,3(33,3-100)$ & & $51,2(22,2)$ & $52(48-68)$ & \\
\hline Justiça & $*$ & $*$ & & $*$ & $*$ & \\
\hline Saúde & $41,1(44,7)$ & $33,3(0-100)$ & & $52,3(21,7)$ & $50(36-68)$ & \\
\hline Segurança & $42,2(41,9)$ & $33,3(0-100)$ & & $52,9(20,9)$ & $50(32-72)$ & \\
\hline Não informado & $33,3(44,7)$ & $0(0-66,7)$ & & $58,2(29,4)$ & $60(36-86)$ & \\
\hline Vacinação da Gripe & & & & & & \\
\hline Sim & $44,7(43,7)$ & $33,3(0-100)$ & 0,354 & $53,5(22,8)$ & $52(36-72)$ & 0,219 \\
\hline Não & $39,8(44,3)$ & $33,3(0-100)$ & & $55,4(20,8)$ & $56(40-72)$ & \\
\hline Não Informado & $*$ & $*$ & & $*$ & $*$ & \\
\hline HAS & & & & & & \\
\hline Sim & $44,1(42,6)$ & $33,3(0-100)$ & 0,752 & $56,9(21,1)$ & $60(46-72)$ & 0,220 \\
\hline Não & $43,2(44,6)$ & $33,3(0-100)$ & & $53,1(22,8)$ & $48(36-72)$ & \\
\hline DM & & & & & & \\
\hline Sim & $45,8(40,1)$ & $33,3(0-83,3)$ & 0,716 & $55,8(23,3)$ & $50(42-74)$ & 0,836 \\
\hline Não & $43,2(44,3)$ & $33,3(0-100)$ & & $54,1(22,3)$ & $52(36-72)$ & \\
\hline Obeso & & & & & & \\
\hline Sim & $54,6(45,3)$ & $66,7(0-100)$ & 0,023 & $58,9(20,1)$ & $60(44-76)$ & 0,073 \\
\hline Não & $38,8(42,6)$ & $33,3(0-100)$ & & $52,4(23)$ & $48(36-68)$ & \\
\hline Asma & & & & & & \\
\hline Sim & $55,6(50,2)$ & $66,7(0-100)$ & 0,473 & $61,3(25,8)$ & $62(36-88)$ & 0,484 \\
\hline Não & $43,1(43,8)$ & $33,3(0-100)$ & & $54(22,2)$ & $52(36-72)$ & \\
\hline
\end{tabular}


Research, Society and Development, v. 10, n. 14, e219101421769, 2021

(CC BY 4.0) | ISSN 2525-3409 | DOI: http://dx.doi.org/10.33448/rsd-v10i14.21769

\begin{tabular}{|c|c|c|c|c|c|c|}
\hline$<18,5$ & * & $*$ & \multirow{6}{*}{0,046} & $54(31,1)$ & $54(32-76)$ & \multirow[t]{6}{*}{0,502} \\
\hline $18,5-24,9$ & $36,2(42)^{a}$ & $16,7(0-66,7)$ & & $51,1(22)$ & $48(36-64)$ & \\
\hline $25-29,9$ & $37(42,4)^{a}$ & $16,7(0-83,3)$ & & $52,9(23,2)$ & $50(36-72)$ & \\
\hline $30-39,9$ & $55,8(46,1)^{\mathrm{b}}$ & $66,7(0-100)$ & & $57,6(19,9)$ & $56(42-76)$ & \\
\hline$>40$ & $66,7(33,3)^{a, b}$ & $66,7(50-83,3)$ & & $65,3(24,1)$ & $68(54-78)$ & \\
\hline Não informado & $48,5(43,1)^{a, b}$ & $66,7(0-83,3)$ & & $61,8(27,2)$ & $60(46-88)$ & \\
\hline \multicolumn{7}{|l|}{ Etilismo } \\
\hline Sim & $37,5(45,4)$ & $0(0-100)$ & \multirow[t]{2}{*}{0,394} & $54,1(22,5)$ & $48(36-74)$ & \multirow[t]{2}{*}{0,837} \\
\hline Não & $44,6(43,7)$ & $33,3(0-100)$ & & $54,3(22,3)$ & $54(36-72)$ & \\
\hline \multicolumn{7}{|l|}{ Dislipidemia } \\
\hline Sim & $37,5(41,9)$ & $33,3(0-83,3)$ & \multirow[t]{2}{*}{0,673} & $57,8(20,6)$ & $56(46-70)$ & \multirow[t]{2}{*}{0,526} \\
\hline Não & $44(44,1)$ & $33,3(0-100)$ & & $54(22,5)$ & $52(36-72)$ & \\
\hline \multicolumn{7}{|c|}{ Doenças Psiquiátricas } \\
\hline Sim & $33,3(39,6)$ & $33,3(0-33,3)$ & \multirow[t]{2}{*}{0,448} & $55,1(26,3)$ & $52(40-68)$ & \multirow[t]{2}{*}{0,796} \\
\hline Não & $44,4(44,3)$ & $33,3(0-100)$ & & $54,2(22)$ & $52(36-72)$ & \\
\hline
\end{tabular}

Legenda: DP - Desvio Padrão. IIQ - Intervalo Interquartil. Teste de Kruskal-Wallis. ${ }^{\text {ab }}$ Subgrupos distintos ao nível de 5\% para o teste de Kruskal-Wallis-Dunn. * Dados insuficientes. Fonte: Autores.

Em relação ao segundo domínio, raça branca (39,5 DP) e parda (47 DP), e atividade estudantil (20,8 DP) foram associados negativamente; enquanto união estável (62,2 DP) obteve relação positiva à Limitação por Aspectos Físicos. Demonstrou-se que as comorbidades não afetaram negativamente os pacientes pós Covid-19, referente a quadros de Dor. Já o uso da oxigenioterapia (25 DP), afetou negativamente estes pacientes.

O Estado Geral de Saúde não demonstrou diferença entre os sexos feminino (55 DP) e masculino (54,6 DP), mas afetou principalmente os solteiros (49,6 DP), estudantes (41,7 DP), e apresentou médias baixas, com déficit moderado a grave, em todos os itens avaliados.

A Vitalidade dos indivíduos do sexo feminino foi mais afetada (49,7 DP), principalmente os portadores de doenças psiquiátricas (47,5 DP). Já referente aos Aspectos Sociais, demonstrou-se que os homens foram mais afetados (51,4 DP), principalmente os estudantes (39,3 DP) e trabalhadores do setor da justiça (34,4 DP).

No sétimo domínio, sexo masculino (41,4 DP), raça branca (37,7 DP), provenientes do município de Socorro (31,7 DP), divorciados (36,1 DP), aposentados (36,8 DP), estudantes (22,2 DP), não obesos (38,8 DP), etilistas (37,5 DP), dislipidêmicos (37,5 DP) e portadores de doenças psiquiátricas (33,3 DP) foram limitados nos Aspectos Emocionais.

No âmbito do domínio da Saúde Mental, o sexo feminino foi mais afetado (52,9 DP), raça amarela (44 DP), aposentados (46,7 DP), estudantes (40,7 DP) e aqueles que apresentaram tosse seca (52,1 DP) e dispneia (49,8 DP) durante convalescência, tiveram pontuação menor no questionário.

\section{Discussão}

Diante do cenário de medo e insegurança vivenciados pela população decorrente da atual crise pandêmica no Brasil, torna-se importante coletar dados acerca da qualidade de vida dos pacientes após período de infecção por Covid-19. Os resultados desse estudo demonstraram que diversas partes da qualidade de vida dos indivíduos foram afetadas. Estudos da Fiocruz (2020) e Rosser (2021) comprovaram que o isolamento social é fator importante de repercussão nos aspectos sociais, econômicos, culturais e históricos ao longo das pandemias. Essas repercussões negativas resultam em baixa qualidade de vida e podem ser explicadas pelo sofrimento psicológico gerado diante aumento da suscetibilidade à infecção, maior risco de mortalidade entre pacientes com doenças crônicas, atraso e inacessibilidade ao atendimento médico, serviços e tratamento, além da péssima manipulação de notícias, muitas vezes sem veracidade ou comprovação científica (Abdelghani et al., 2021; Kharshiing et al., 2020). 
Fatores associados ao gênero e estilo de vida podem piorar a qualidade de vida após o diagnóstico de infecção pelo Covid-19. A maioria dos entrevistados foram adultos, que estudam ou trabalham. A mudança repentina das atividades diárias, que foram amplamente limitadas a permanência dentro do domicilio durante período de quarentena, evidentemente teve um impacto sobre os respondentes. Além disso, aulas online e arranjos de trabalho em casa podem ser estressantes, intensificados ou diminuídos pelas condições de vida (Aquino et al., 2021; Mota et al., 2021).

Em primeira análise, os participantes apresentaram escore abaixo de 50 DP nos domínios de Aspectos Físicos e Aspectos Emocionais, demonstrando moderado a grave acometimento, estando abaixo da média de qualidade de vida esperada. O domínio relativo à Saúde Mental avalia a capacidade psicológica do indivíduo no enfrentamento dos desafios inerentes à condição humana, como capacidade de lidar com fatores estressantes, por exemplo, instabilidade no emprego, doenças graves, traumas, dentre outros (Alvarenga et al., 2020). Nesse contexto, as mulheres foram mais acometidas, com risco aumentado de ter baixa qualidade de vida nas dimensões Saúde Mental e Vitalidade, e baixos índices em Capacidade Funcional e Estado Geral de Saúde, com pouca diferença entre os gêneros nesses dois últimos. Isso pode ocorrer devido a maior pressão social nos cuidados familiares, com mulheres assumindo novas funções devido a pandemia, gerando sobrecarga emocional. Estudo semelhante realizado com a população chilena, demonstrou que esse grupo obteve menor qualidade de vida na saúde em geral, além de piora na função física e presença de dor no corpo (Guzmán-Muñoz et al., 2020). Consequentemente, as mulheres são uma preocupação no Covid-19 e necessitam de tempos de reabilitação mais longos.

Em contraponto, verificou-se que o desempenho do sexo masculino nos domínios de Aspectos Sociais e Aspectos Emocionais foram ligeiramente piores. A pressão de uma sociedade patriarcal, em que esse grupo ainda assume mais responsabilidades perante família e sociedade, o medo do desemprego e uma maior exposição em atividades ocupacionais são possíveis fatores que justificam esse acometimento (Silva et al., 2021; Guirado et al., 2021).

A pandemia afetou significativamente as dinâmicas escolares. Destarte, os estudantes apresentaram queda na qualidade de vida referente aos Aspectos Físicos, Estado Geral de Saúde, Saúde Mental, Aspectos Sociais e Aspectos Emocionais. O severo acometimento pode estar muito relacionado à mudança mais drástica de rotina, com escassa ou ausente socialização com amigos e alterações na grade curricular. Segundo um estudo realizado nas Filipinas, tais entrevistados apresentaram níveis aumentados de estresse, com níveis baixos a moderados de cansaço e energia. Decorreu-se que isso ocorre porque as aulas online são mais difíceis de realizar, já que se trabalha sozinho, e pelo estímulo aos hábitos não saudáveis como sedentarismo (Aquino et al., 2021).

No mais, percebeu-se como a pandemia afetou os extremos etários: os estudantes, citados anteriormente e formados principalmente por adultos jovens, e aposentados, com grande contingente de idosos. O acometimento negativo do bem estar dos aposentados está relacionado ao medo de morrer, devido a notícias da mídia relacionadas a maior mortalidade em grupos idosos e nos portadores de comorbidades, além do isolamento social, visto que indivíduos desses grupos não estão inseridos em profissões essenciais. Revisão de literatura não obteve dados suficientes acerca dessa temática.

A pesquisa demonstrou que os domínios de Limitação por Aspectos Físicos, Aspectos Emocionais e Vitalidade sofreram intervenção negativa nesse período e o mesmo ocorreu com os divorciados e solteiros. Em contrapartida, pesquisa realizada sobre repercussões da pandemia na população brasileira demonstrou que indivíduos com parceiros apresentaram melhores escores (exceto para o domínio social - que foi semelhante) quando comparados a solteiros (Silva et al., 2021)

Nível educacional mais alto foi associado a menor impacto na saúde mental, considerando os aspectos psicológicos e físicos. Advém que a educação superior está associada à felicidade e satisfação e afetam fortemente a renda, assim como baixo nível de escolaridade tem maior correlação com desemprego (Teotônio et al., 2020). Corroborando esse fato, em nossa 
pesquisa, ensino fundamental incompleto e ensino médio incompleto estão relacionados aos menores índices de Vitalidade, Limitação por Aspectos Sociais e Saúde Mental.

Com relação às comorbidades, pacientes com hipertensão, diabetes e asma apresentaram menores índices de Limitação por Aspectos Físicos. Etilismo, dislipidemia e doença psiquiátrica estiveram mais relacionadas aos Aspectos Emocionais. Muitas dessas doenças têm sido descritas como marcadores de gravidade da doença em pacientes com Covid-19. Estudos com indivíduos hipertensos afirmam que a expressão da enzima conversora de angiotensina 2, frequentemente aumentada nesses pacientes, e a ativação do sistema renina-angiotensina podem estar envolvidas na entrada do vírus na célula ou na resposta inflamatória (Temperoni et al., 2021). Referente a Diabetes e suas complicações, verifica-se aumento do risco de morbidade e mortalidade durante infecções agudas devido à supressão das funções imunes inata e humoral. Níveis de hemoglobina glicada (HbA1c) > 9\% foram associados a um aumento de $60 \%$ no risco de hospitalização e gravidade relacionada à pneumonia durante a infecção bacteriana (Singh et al., 2020). Além disso, pessoas com doença mental e etilistas possuem maior predisposição a pneumonia e quadros clínicos severos. No entanto, não há dados científicos suficientes que confirmem associação entre asma e piora do desconforto respiratório desses pacientes (Temperoni et al., 2021).

Em estudo realizado com a população chinesa (Chen et al., 2020), o sobrepeso e obesidade foram preditores dos domínios abaixo do percentil 50, indicando associação entre IMC e deficiência física. Além disso, em pesquisas com o vírus Influenza A, a obesidade pode piorar a gravidade das doenças respiratórias, e ainda, os pacientes com Covid-19 e IMC $\geq 35$ possuem maior risco de ventilação mecânica, em comparação com aqueles com IMC <25 (Temperoni et al., 2021). Contrariando essas estatísticas, o presente estudo não demonstrou prejuízo na qualidade de vida dos entrevistados baseado em seu IMC.

A presença de dor, sendo ela crônica ou não, está relacionada a repercussões negativas na vida da população, limitando a vida dos seus portadores. A maioria dos entrevistados negou presença de dor ou, caso presente, não os impedia de realizar atividades diárias, demonstrando pouca necessidade de intervenção, o que caracteriza um indicador positivo de qualidade de vida. Os grupos que demonstraram influência negativa da dor em seu cotidiano foram os que necessitaram de internação, uso de oxigenoterapia e portadores de doenças psiquiátricas (Guzmán-Muñoz et al., 2020).

\section{Considerações Finais}

As incertezas sobre o futuro durante um período pandêmico tendem a diminuir os escores médios de qualidade de vida e historicamente representam um desafio para governos e indivíduos.

Nosso estudo demonstrou prejuízo na qualidade de vida dos pacientes principalmente em idosos, estudantes, mulheres e divorciados, que tiveram sua rotina modificada, com consequências nos aspectos psicológicos e físicos. O maior impacto nesse grupo sinaliza segmentos demográficos de maior vulnerabilidade, a demandar aplicação e aprimoramento de estratégias de preservação e atenção à saúde mental durante a pandemia. Faz-se necessário um gerenciamento psicológico que possa atender principalmente esses grupos prioritários, durante todo período da doença, salientando a necessidade de propostas de organização e implementação de serviços de atenção à saúde mental em novos moldes.

A pandemia do Covid-19 ainda está em curso e os achados dessa pesquisa precisam ser confirmados e investigados com maiores estudos populacionais. Faz-se necessária uma avaliação mental pré-Covid-19 para efeito comparativo mais preciso e a não inclusão de crianças invoca a necessidade de investigação futura. Ademais, o baixo número de participantes hospitalizados impossibilitou avaliação dos impactos gerados pelo período de hospitalização e suas consequências, como uso de oxigenoterapia e tratamentos mais invasivos. 
Research, Society and Development, v. 10, n. 14, e219101421769, 2021

(CC BY 4.0) | ISSN 2525-3409 | DOI: http://dx.doi.org/10.33448/rsd-v10i14.21769

Os dados coletados forneceram uma visão mais sensível e científica da qualidade de vida dos indivíduos, ajudando a melhorar o atendimento mediante ações de saúde mental coletivas e individuais que possibilitem ressignificação do cotidiano da população. O conhecimento da qualidade de vida da população durante a pandemia permitirá pesquisas futuras comparando o impacto da atualidade com possíveis eventos pandêmicos futuros.

\section{Referências}

Abdelghani, M., G. Hamed, M., \& Said, A. (2021). Evaluation of perceived fears of COVID-19 virus infection and its relationship to health-related quality of life among patients with diabetes mellitus in Egypt during pandemic: A developing country single-center study. The Japan Diabetes Society 2021. https://doi.org/10.1007/s13340-021-00511-8

Alvarenga, R., Martins, G. C., Dipe, E. L., Campos, M. V. d. A., Passos, R. P., Lima, B. N., Camargo, L. B. d., Sílio, L. F., Oliveira, J. R. L. d., Vilela Junior, G. d. B., \& Fileni, C. H. P. (2020). Percepção da qualidade de vida de professores das redes públicas e privadas frente à pandemia do covid-19. Centro de Pesquisas Avançadas em Qualidade de Vida, (v12n3), 1-8. https://doi.org/10.36692/cpaqv-v12n3-1

Alves, R. S. S., Silva, M. P. B., Leite, A. C., Silva, J. K. A. d., Silvestre, F. E. R., Silva, L. d. C., Fagundes, G. R. S., Lobão, A. G. S. R., Dalben, Y. R., Assis, T. S. d., Aragão, D. F. B., Paulo, M. d. S., Oliveira, M. d. S., Silva, M. d. L., Lima, F. N., Santos, B. K. O., \& Freitas, M. G. T. d. (2021). Impacto do isolamento social na sociedade: Recomendações em tempos de COVID-19. Research, Society and Development, 10(1), Artigo e57910111281. https://doi.org/10.33448/rsd-v10i1.11281

Aquino, M., Lee, K., Lacap, A., Diaz, M., \& Cadorna, G. (2021). Measuring Health-Related Quality of Life in the Time of COVID-19 with SF-36: A Population-Based Study in the Philippines. Health-Related Quality of Life During COVID-19.

Barros, M. B. d. A., Lima, M. G., Malta, D. C., Szwarcwald, C. L., Azevedo, R. C. S. d., Romero, D., Souza Júnior, P. R. B. d., Azevedo, L. O., Machado, Í. E.,

Damacena, G. N., Gomes, C. S., Werneck, A. d. O., Silva, D. R. P. d., Pina, M. d. F. d., \& Gracie, R. (2020). Relato de tristeza/depressão, nervosismo/ansiedade e problemas de sono na população adulta brasileira durante a pandemia de COVID-19. Epidemiologia e Serviços de Saúde, 29(4). https://doi.org/10.1590/s1679-49742020000400018

Bettine de Almeida, M. A., Gutierrez, G. L., \& Marques, R. (n.d.). Qualidade de vida: definição, conceitos e interfaces com outras áreas, de pesquisa. Escola de Artes, Ciências e Humanidades - EACH/USP. http://www.each.usp.br/edicoes-each/qualidade_vida.pdf (Obra original publicada em 2012)

Brasil - OPAS/OMS | Organização Pan-Americana da Saúde. (n.d.). PAHO/WHO | Pan American Health Organization. https://www.paho.org/pt/brasil

Castro, M. d., Caiuby, A. V. S., Draibe, S. A., \& Canziani, M. E. F. (2003). Qualidade de vida de pacientes com insuficiência renal crônica em hemodiálise avaliada através do instrumento genérico SF-36. Revista da Associação Médica Brasileira, 49(3), 245-249. https://doi.org/10.1590/s010442302003000300025

Castro, P. R. M., Souza, S. C. d., Damasceno, R. A., Nascimento, G. M. d., \& Farias, R. R. S. d. (2021). Impactos psicológicos em adultos durante a pandemia de COVID-19: Uma revisão integrativa. Research, Society and Development, 10(11), Artigo e195101118546. https://doi.org/10.33448/rsd-v10i11.18546

Chen, K.-Y., Li, T., Gong, F.-H., Zhang, J.-S., \& Li, X.-K. (2020). Predictors of health-related quality of life and influencing factors for COVID-19 patients, a follow-up at one month. Frontiers in Psychiatry, 11. https://doi.org/10.3389/fpsyt.2020.00668

Coronavirus disease (COVID-19) - World Health Organization. (n.d.). WHO | World Health Organization. https://www.who.int/emergencies/diseases/novelcoronavirus-2019? gclid=CjwKCAjw-sqKBhBjEiwAVaQ9ay_Xgf2xSIGai8d4vkEsAdTP8O2WwZuFCVwb0CCywoJJE_s4QoXZbxoCVCEQAvD_BwE

Dias, I. C., Almeida, C. H. d., Melo, É. M. M., Dias, H. C., Luz, I. S., Santos, J. L. D., Barbosa, J. F., Zanetti, L. F., Filho, R. M. N., \& Soares, G. F. G. (2021). Os impactos da pandemia de COVID-19 na saúde mental da população. Revista Eletrônica Acervo Científico, 30 , Artigo e8218. https://doi.org/10.25248/reac.e8218.2021

Dinno, A. (2015). Nonparametric pairwise multiple comparisons in independent groups using dunn's test. The Stata Journal: Promoting Communications on Statistics and Stata, 15(1), 292-300. https://doi.org/10.1177/1536867x1501500117

Ferreira, L. N., Pereira, L. N., da Fé Brás, M., \& Ilchuk, K. (2021). Quality of life under the COVID-19 quarantine. Quality of Life Research. https://doi.org/10.1007/s11136-020-02724-x

Garratt, A. M., Ghanima, W., Einvik, G., \& Stavem, K. (2021). Quality of life after COVID-19 without hospitalisation: Good overall, but reduced in some dimensions. Journal of Infection, 82(5), 186-230. https://doi.org/10.1016/j.jinf.2021.01.002

Goulart Rosa, R. (2021). Qualidade de vida e desfechos em longo prazo após hospitalização por COVID-19: Protocolo para um estudo de coorte prospectivoQualidade de vida e desfechos em longo prazo após hospitalização por COVID-19: Protocolo para um estudo de coorte prospectivo. Revista Brasileira de Terapia Intensiva. https://doi.org/10.5935/0103-507X.20210003

Guirado, G. M. d. P., Guirado, V. M. d. P., Oliveira, E., Queiroz, P. E., \& Garcia, R. (2021). Avaliação da qualidade de vida de trabalhadores antes e durante a pandemia de COVID-19 por meio do questionário SF-36. Revista de Gestão em Sistemas de Saúde, 10(1), 84-105. https://doi.org/10.5585/rgss.v10i1.17820

Guo, L., Lin, J., Ying, W., Zheng, C., Tao, L., Ying, B., Cheng, B., Jin, S., \& Hu, B. (2020). Correlation study of short-term mental health in patients discharged after coronavirus disease 2019 (COVID-19) infection without comorbidities: A prospective study. Neuropsychiatric Disease and Treatment, Volume 16, 2661-2667. https://doi.org/10.2147/ndt.s278245 
Research, Society and Development, v. 10, n. 14, e219101421769, 2021

(CC BY 4.0) | ISSN 2525-3409 | DOI: http://dx.doi.org/10.33448/rsd-v10i14.21769

Guzmán-Muñoz, E., Concha-Cisternas, Y., Oñate-Barahona, A., Lira-Cea, C., Cigarroa-Cuevas, I., Méndez-Rebolledo, G., Castillo-Retamal, M., ValdésBadilla, P., \& Zapata-Lamana, R. (2020). Factores asociados a una baja calidad de vida en adultos chilenos durante la cuarentena por COVID-19. Revista médica de Chile, 148(12), 1759-1766. https://doi.org/10.4067/s0034-98872020001201759

He, Y., Yu, R., \& Ren, J. (2021). The correlation between psychiatric disorders and covid-19: A narrative review. Psychiatria Danubina, 33(1), 76-85. https://doi.org/10.24869/psyd.2021.76

Hanusz, Z., \& Tarasinska, J. (2016). Shapiro-wilk test with known mean. Statistical Journal. https://www.ine.pt/revstat/pdf/rs160105.pdf

Kharshiing, K. D., Kashyap, D., Gupta, K., Khursheed, M., Shahnawaz, M. G., Khan, N. H., Uniyal, R., \& Rehman, U. (2020). Quality of life in the COVID19 pandemic in india: Exploring the role of individual and group variables. Community Mental Health Journal. https://doi.org/10.1007/s10597-020-00712-6 Ladeia, D. N., Silva, A. F. d., Gonçalves, B. B. S., Damasceno, C. M. C., Vieira, J. P. G., Silva, J. A. L., Lopes, L. M. d. M., Queiroz, N. O., \& Lopes, A. G. (2020). Análise da saúde mental na população geral durante a pandemia de Covid-19. Revista Eletrônica Acervo Saúde, (46), Artigo e3925. https://doi.org/10.25248/reas.e3925.2020

Laguardia, J., Campos, M. R., Travassos, C., Najar, A. L., Anjos, L. A. d., \& Vasconcellos, M. M. (2013). Brazilian normative data for the Short Form 36 questionnaire, version 2. Revista Brasileira de Epidemiologia, 16(4), 889-897. https://doi.org/10.1590/s1415-790x2013000400009

Lestari, R., \& Setyawan, F. E. B. (2021). Mental health policy: Protecting community mental health during the COVID-19 pandemic. Journal of Public Health Research, 10(2). https://doi.org/10.4081/jphr.2021.2231

Lima, S. O., Silva, M. A. d., Santos, M. L. D., Moura, A. M. M., Sales, L. G. D., Menezes, L. H. S. d., Nascimento, G. H. B., Oliveira, C. C. d. C., Reis, F. P., \& Jesus, C. V. F. d. (2020). Impactos no comportamento e na saúde mental de grupos vulneráveis em época de enfrentamento da infecção COVID-19: Revisão narrativa. Revista Eletrônica Acervo Saúde, (46), Artigo e4006. https://doi.org/10.25248/reas.e4006.2020

Lou, Y., \& Yuen, S. Y. (2018). Evolução das funções de benchmark usando o teste Kruskal-wallis. Proceedings of the Genetic and Evolutionary Computation Conference Companion, 1337-1341. https://dl.acm.org/doi/10.1145/3205651.3208257

Mota, I. A., Oliveira Sobrinho, G. D. d., Morais, I. P. S., \& Dantas, T. F. (2021). Impact of COVID-19 on eating habits, physical activity and sleep in Brazilian healthcare professionals. Arquivos de Neuro-Psiquiatria, 79(5), 429-436. https://doi.org/10.1590/0004-282x-anp-2020-0482

Organización Mundial de la Salud. (n.d.). Promoción de la Salud. http://apps.who.int/iris/bitstream/handle/10665/67246/WHO_HPR_HEP_98.1 _spa.pdf;jsessionid=E750577929E092B86720C72F5AC28468? sequence=1

Ping, W., Zheng, J., Niu, X., Guo, C., Zhang, J., Yang, H., \& Shi, Y. (2020). Evaluation of health-related quality of life using EQ-5D in China during the COVID-19 pandemic. Plos One, 15(6), Artigo e0234850. https://doi.org/10.1371/journal.pone.0234850

Qi, M., Li, P., Moyle, W., Weeks, B., \& Jones, C. (2020). Physical activity, health-related quality of life, and stress among the chinese adult population during the COVID-19 pandemic. International Journal of Environmental Research and Public Health, 17(18), 6494. https://doi.org/10.3390/ijerph17186494

Saverino, A., Zsirai, E., Sonabend, R., Gaggero, L., Cevasco, I., Pistarini, C., \& Cremonesi, P. (2021). Health related quality of life in COVID-19 survivors discharged from acute hospitals: Results of a short-form 36-item survey. F1000Research, 10, 282. https://doi.org/10.12688/f1000research.50781.1

Silva, M. d. N. R. M. d. O., \& Pimentel, A. d. S. G. (2021). Desvelando o isolamento social no cotidiano vivido na pandemia da COVID-19. Research, Society and Development, 10(3), Artigo e59910314132. https://doi.org/10.33448/rsd-v10i3.14132

Silva, R. d. O. e., Pereira, J. N., \& Milan, E. G. P. (2021). Avaliação da qualidade de vida com o instrumento SF-36 durante a pandemia do COVID-19: Um estudo piloto. Research, Society and Development, 10(9), Artigo e17110917596. https://doi.org/10.33448/rsd-v10i9.17596

Singh, A. K., Gupta, R., Ghosh, A., \& Misra, A. (2020). Diabetes in COVID-19: Prevalence, pathophysiology, prognosis and practical considerations. Diabetes \& Metabolic Syndrome: Clinical Research \& Reviews, 14(4), 303-310. https://doi.org/10.1016/j.dsx.2020.04.004

Suryavanshi, N., Kadam, A., Dhumal, G., Nimkar, S., Mave, V., Gupta, A., Cox, S. R., \& Gupte, N. (2020). Mental health and quality of life among healthcare professionals during the COVID-19 pandemic in India. Brain and Behavior, 10(11). https://doi.org/10.1002/brb3.1837

Temperoni, C., Grieco, S., Pasquini, Z., Canovari, B., Polenta, A., Gnudi, U., Montalti, R., \& Barchiesi, F. (2021). Clinical characteristics, management and health related quality of life in young to middle age adults with COVID-19. BMC Infectious Diseases, 21(1). https://doi.org/10.1186/s12879-021-05841-1

Teotônio, I., Hecht, M., Castro, L. C., Gandolfi, L., Pratesi, R., Nakano, E. Y., Puppin Zandonadi, R., \& Pratesi, C. B. (2020). Repercussion of COVID-19 pandemic on brazilians' quality of life: A nationwide cross-sectional study. International Journal of Environmental Research and Public Health, 17(22), 8554. https://doi.org/10.3390/ijerph17228554 